\title{
Exosomes transfer p53 between cells and can suppress growth and proliferation of $\mathbf{p 5 3}$ negative cells
}

\author{
V. S. Burdakov ${ }^{a, b}$, R. A. Kovalev ${ }^{a}$, R. A. Pantina ${ }^{a}$, E. Yu. Varfolomeeva ${ }^{a}$, E. M. \\ Makarov $^{c}$, and M. V. Filatov ${ }^{a, d}$, *
}

${ }^{a}$ Petersburg Nuclear Physics Institute named by B. P. Konstantinov of National Research Centre "Kurchatov Institute", Gatchina, Leningrad oblast, 188300 Russia

${ }^{b}$ Department of Biophysics, Peter the Great St. Petersburg Polytechnic University, St. Petersburg, 194064 Russia

${ }^{c}$ College of Health and Life Sciences, Brunel University, London, Uxbridge, United Kingdom

${ }^{d}$ St. Petersburg Institute of Phthisiopulmonology, St. Petersburg, 191036 Russia

*e-mail:fil_53@mail.ru

\begin{abstract}
Exosomes are nanosized vesicles that are secreted by many types of cells. We have found that exosomes secreted by HEK293 and HT-1080 can suppress growth and proliferation of p53-deficient cells. Upon overexpression of exogenous p53-GFP in HEK293 cells, we observed p53 protein in exosomes that were secreted by these cells. We also found endogenous p53 in exosomes that were secreted by HT-1080 cells with a higher level of p53 expression. We were able to detect endogenous p53 protein in exosomes that originated from human plasma and were transferred to p53-deficient cells. Our findings indicate that p53 protein can be transferred between cells and may play an important physiological role.
\end{abstract}

\section{INTRODUCTION}

Exosomes are nanosized extracellular membrane vesicles that are released from multivesicular bodies into the extracellular space by exocytosis (Huang et al., 2013). Depending on the cells that produce them, exosomes can differ both in the composition of proteins, lipids, mRNAs, different noncoding RNAs, and miRNAs and in their biological properties. Being involved in intercellular communication, exosomes can induce both functional and epigenetic changes by transferring RNA and specific proteins between cells (Grange et al., 2011; Kobayashi et al., 2014). Numer- ous studies demonstrate that increased expression of a variety of genes can lead to the occurrence and accu- mulation of their protein products in exosomes (Gra- ner et al., 2009; Mukhopadhyay and Mak, 2009; Stau- bach et al., 2009; Meckes et al., 2010; Adamczyk et al., 2011; Higginbotham et al., 2011). Today, it being suggested that exosomes can be involved via different mechanisms in the development of cancerous tumors, e.g., in preparing a metastatic niche (Webber et al., 2015; Yu et al., 2015). The identification of key factors that determine the formation of the exosome proteome is important for the identification of novel mechanisms, which can be involved in the formation, development, and suppression of tumors (Raimondo et al., 2011; Ung et al., 2014).

The p53 protein is of particular interest due to its prominent role in tumor suppression, because of which it is referred to as "the guardian of the genome" in the literature (Liang et al., 2013). Over more than 35 years of studies, it has been found that p53 is a transcription factor that controls the cell cycle and cell death following oncogene activation, DNA damage, and other types of stress (Vousden and Prives, 2009). Some authors believe that p53 can enhance the secretion of exosomes by activating the transcription of several genes that are involved in their production (Yu et al., 2006; Lespagnol et al., 2008; Naghibalhossaini et al., 2011; Lim et al, 2012). However, to date, p53 has not been found in 
exosomes that are secreted by cell lines (Kalra et al., 2012; Keerthikumar et al., 2015), with only one study demonstrating its presence in exosomes of human blood plasma (Jorgensen et al., 2015). Thus, this problem requires a more detailed study. The presence or absence of this protein in exosomes can depend on its expression in producer cells. This study was aimed at detection of p53 in exosomes that are secreted by cells with natural and artificially increased expression of this gene and at increasing the sensitivity of the method for detection of p53 in exosomes of human body fluids (blood plasma). To confirm the presence of p53 in exosomes of blood plasma, we employed an approach that uses accumulation of exosomes in recipient cells that do not produce the protein under study. Moreover, to test the hypothesis of the possibility of suppression of carcinogenesis by exosomes that contain p53, we analyzed how exosomes that are obtained from cell lines with wild-type p53 (HEK293 and HT-1080) affect the proliferation of p53-negative cells of cancer lines (GL-V or K562).

\section{MATERIAL AND METHODS}

Cell lines, cultivation conditions. This study was performed on passaged cultures of human cells: HEK293 (human embryonic kidney cells), GFP-p53 4 Y126- HEK293 (an HEK293 clone that stably expresses p53 with a single amino-acid deletion), HT-1080 (fibrosarcoma), Gl-V (a primary culture of glioma cells that is obtained in our laboratory), and K-562 (chronic myelogenous leukemia) (Table 1). The cells were cultivated in DMEM/F12 medium (Biolot, Russia), which was supplemented with $10 \%$ fetal bovine serum (Biolot, Russia), without antibiotics in a $5 \% \mathrm{CO} 2$ atmosphere at $37^{\circ} \mathrm{C}$. The K-562 suspension culture that was obtained from the collection of the Institute of Cytology of the Russian Academy of Sciences was cultivated in RPMI 1640 medium (Biolot, Russia), which was supplemented with $10 \%$ foetal bovine serum (Biolot, Russia). At a combined cultivation of cells of all the cell lines with isolated exosomes, the exosome concentration was $10^{13}-10^{14}$ exosomes $/ \mathrm{mL}$.

Assessment of survival rate of cells. The cells were suspended using a Trypsin-Versene solution, and the survival rate was quantitatively assessed by counting the number of cells using a Scepter handheld automated cell counter (Millipore, United States).

Isolation of exosomes in in vitro systems. As the cells grew, the culture conditioned medium was collected and sequentially centrifuged at 2000 and $20000 \mathrm{~g}$ to remove dead cells and their debris until $500 \mathrm{~mL}$ was accumulated. Then, the accumulated conditioned medium was used to isolate exosomes by ultracentrifugation. The ultracentrifugation was carried out on a Beckman coulter centrifuge (45Ti rotor) at $100000 \mathrm{~g}$ for $2 \mathrm{~h}$. After the centrifugation, the sediment was suspended in the maximum volume of phosphate buffer saline (PBS) and centrifuged again under the same conditions. The exosome sediment that was obtained was used for further analysis.

Cloning. HEK293 cells were transfected by the p53 $\mathrm{Y} 126$ plasmid according to the conventional technique using a Effectene Transfection Reagent kit (Qiagen, Germany). Two days after the transfection, the cells were passaged into Carrel flasks and supplemented with G418 at $400 \mu \mathrm{g} / \mathrm{mL}$. In the presence of G418, the cells were cultivated for 10 days. Then, the cells were repassaged into 96well plates for cloning, i.e., obtaining cell lines that are descendants of a single cell. One of the clones that produce mutant GFP-p53 was used in further experiments. To visualize intracellular GFP, the clone cells were passaged into glass-bottom dishes that were $35 \mathrm{~mm}$ in diameter (MatTek Corp., United States). Live-cell analysis was performed.

Identification of p53 in cells. GL-V cells were grown on coverslips in plates in DMEM/F12 medium (Biolot, Russia), which was supplemented with 10\% fetal bovine serum (Biolot, Russia), in a 
$\mathrm{CO} 2$ incubator at $37^{\circ} \mathrm{C}$. After the incubation with exosomes the coverslips had the medium washed from them $1 \times$ PBS and were fixed for 10 min with cold $4 \%$ formaldehyde at $4{ }^{\circ} \mathrm{C}$. Then, the coverslips were washed three times with $1 \times \mathrm{PBS}$ for $15 \mathrm{~min}$. The preparations were treated with $0.5 \%$ Triton X100 for 10 min and blocked with 5\% bovine serum albumin (BSA, Biolot, Russia) in PBS for 15 min at room temperature. Monoclonal antibodies against p53 (Sigma, Japan) were diluted 1:2000 in 1\% BSA in $1 \times$ PBS. The preparations were stained at $4{ }^{\circ} \mathrm{C}$ overnight. After the staining with primary antibodies, the coverslips were washed with $1 \times$ PBS (twice, for $15 \mathrm{~min}$ ). Secondary antibodies (goat anti-mouse Alexa Fluor594, Invitrogen, United States) were diluted 1:500 in 1\% BSA in 1× PBS. The samples were stained with the secondary antibodies for $1 \mathrm{~h}$ at room temperature. Then, the coverslips were washed in $1 \times$ PBS (five times for $20 \mathrm{~min}$ ) and stored in $1 \times$ PBS overnight at $4^{\circ} \mathrm{C}$. The samples were embedded into Vectashield medium with DAPI $(1.5 \mu \mathrm{g} / \mathrm{mL})$ (Vector Laboratories, Inc., United States), and, 1 day after this, they were analyzed on a Leica confocal microscope (Germany).

Assessment of expression of the TP53 gene. The level of the p53 protein was assessed by immunoblotting. For this, cells $\left(1-2 \times 10^{6}\right)$ were washed twice with phosphate buffer saline (PBS) and incubated at $4^{\circ} \mathrm{C}$ for 30 min with a lysing buffer $(10 \mathrm{mM}$ Tris- $\mathrm{HCl} \mathrm{pH} 7.4,0.1 \%$ Triton X-100, $5 \mathrm{mM}$ phenylmethylsulfonyl fluoride (PMSF), $5 \mathrm{mM} \mathrm{MgCl} 2,5 \mathrm{U} / \mathrm{mL}$ DNase I, $20 \mathrm{mM} \beta$-mercaptoethanol). The lysates that were obtained were boiled in a standard loading buffer $(0.25 \mathrm{M}$ Tris, $\mathrm{pH} 6.8,8 \%$ SDS, $40 \%$ glycerin, $20 \% \beta$-mercaptoethanol, $0.2 \%$ bromophenol blue) for $5 \mathrm{~min}$. Protein electrophoresis was performed in a $10 \%$ polyacrylamide gel that contained $0.1 \%$ SDS with further protein transfer to a PVDF membrane. After the transfer, the membrane was soaked in methanol (10 s) and stained for 1 min in a $0.1 \%$ Coomassie $\mathrm{R}$ solution in $30 \%$ methanol that contained $10 \%$ acetic acid; then, it was washed twice in 50\% methanol (for $1 \mathrm{~min}$ ). The visualization of the proteins on a membrane makes it possible to evaluate the transfer and the loading of the tracks. The membrane was completely dried for further immunodetection without high background. The visualization of p53 on the membrane was carried out using monoclonal antibodies (mouse anti-p53) by blue dry western (Naryzhny, 2009).

\section{RESULTS}

The absence of data in the literature on the presence of p53 in exosomes may be due to its low expression in cells. To study whether p53 can be found in exosomes, we artificially enhanced its expression in producer cells. To obtain a cell line that stably expresses $\mathrm{p} 53$, we used a plasmid that carried p53 with a mutation resulting in the tyrosine deletion at the 126 position of the peptide chain ( $53 \Delta Y 126$ ) and leading to a decrease in the functional activity of the protein under study. To create a plasmid that carries the mutant gene, the pEGFP-N1 vector was used; this made it possible to track the expression of the protein of interest in vitro. We chose to transfect this plasmid into HEK293 cells with low expression of wild-type p53. After selection of the clone, we obtained a stable cell line GFPp53 $\triangle$ Y126-HEK293 with high expression of GFP-p53 $\Delta$ Y126 (Fig. 1a). To determine whether exosomes that were secreted by GFP-p53 $\Delta$ Y126-HEK293 contained GFP-p53 $\Delta$ Y126 we isolated exosomes from the conditioned medium where the cells had grown by ultracentrifugation as described earlier (Lasser et al., 2012; Shtam et al., 2013). To confirm the presence of GFP-p53 $\Delta$ Y126 in exosomes that were secreted by GFP-p53 $\triangle$ Y126-HEK293 cells, we used immunoblotting. Control was represented by whole cell lysates of HEK293 and GFP-p53 4 Y126-HEK293 cells that were prepared in parallel with the exosome preparation. As can be seen in Fig. 1b, after staining with monoclonal antibodies against p53, the exosomes and the GFP-p53 $\triangle$ Y126-HEK293 cells had both the GFPp53 5126 protein, $80 \mathrm{kDA}$, and the p53 protein found (Fig. 1b).

These data made it possible for us to raise a question whether endogenous p53 can be found in exosomes and whether it can be transferred via exosomes to recipient cells. The fact that the GFP- 
p53 5126 protein was found in exosomes that were secreted by the GFP-p53 $\Delta$ Y126-HEK293 cells made it possible to propose that the probability of p53 detection in exosomes correlate with its expression in the producer cells. To test this hypothesis, we took several cell lines with different expression of p53, HT-1080 with high expression and HEK293 with low expression. The K562 and GL-V lines where p53 is absent were used as a control. Exosome preparations were obtained from these lines by conventional techniques; the presence (absence) of p53 in the exosomes was tested by immunoblotting using monoclonal antibodies. The cell lysates of each of the lines were used as a control. The p53 protein was only found in exosomes that were secreted by the HT-1080 cell line with high expression of this protein (Fig. 2a). To confirm this result and to study p53 transfer between cells via exosomes, exosomes that were produced by the HT-1080 line were added to the GL-V cell culture. After incubation with the exosomes, the cells were thoroughly washed and fixed with formalin for further immunofluorescent detection of p53 using specific monoclonal antibodies. Cells of the same line that were not incubated with the HT-1080 exosomes were used as a control. Confocal images that were obtained after the application of antibodies against p53 demonstrated fluorescence inside the GL$\mathrm{V}$ cells that were treated with the HT-1080 exosomes, which was never observed in untreated cells. This indicates the occurrence and accumulation of p53 in recipient cells upon their incubation with the HT-1080 exosomes (Fig. 2b).

After the detection of p53 in exosomes that were secreted at least by one cell line, we decided to test whether it is possible to detect this protein in exosomes of human body fluids, e.g., to confirm its presence in exosomes of blood plasma (Jorgensen et al., 2015). Immunoblotting has not given a positive result: no p53 was observed in exosomes of blood plasma. However, under the assumption of rather low sensitivity of the applied method, we decided to test the delivery of p53 by the exosomes of human blood plasma and its accumulation in the GL-V cells using confocal microscopy. For this, after the combined incubation of the GL-V cells that had no endogenous p53 with the exosomes that were isolated from the blood plasma, immunofluorescent labeling with antibodies against p53 was performed. We were able to identify in the sample cells that contained p53 obtained via exosomes (Fig. $3)$.

The presence of wild-type p53 in exosomes raises the question of its functional role, in particular, of the ability of these exosome to affect the growth of cells that do not have p53. To answer this question, we isolated exosomes that were obtained from four lines with different statuses of p53 by multistage centrifugation as described earlier. For this stage of the study we chose the K562 and GL-V lines that do not synthesize p53 and the HT-1080 and HEK293 lines that contain wild-type p53. HT1080, HEK293, K562, and GL-V cells were seeded into 24-well plates at the same concentration. Then, equal quantities of exosomes that were isolated from one of the cell lines were added to the all cell lines. Ten days after the addition of the exosomes the number of living cells was calculated for all the cell lines. The results of evaluation of the survival rate of the cells are given in Fig. 4. The addition of exosomes that were obtained from all the cell lines that were used in the experiment did not affect the survival of the HT-1080 and HEK293 cells. However, the addition of the HT-1080 and HEK293 exosomes to the K562 and GL-V cells was observed to lead to a decrease in the survival of the K562 and GL-V cells; the addition of their own exosomes did not affect the survival of the K562 and GL-V cells (Fig. 4). The obtained results make it possible to hypothesize that exogeneous p53 that enters cells in exosomes can suppress growth of p53-negative cells.

\section{DISCUSSION}

Eukaryotic cells are known to interact with each other not only by means of a direct contact, but also by releasing vesicles including exosomes, microvesicles, apoptotic bodies, etc. (Abels and 
Breakefield, 2016). Exosomes contain a wide range of functional proteins, RNA, and miRNA, and they are actively released by exocytosis from almost all cell types, including dendritic cells, lymphocytes, and tumor cells (Raposo and Stoorvogel, 2013). Moreover, the ability of exosomes to effectively transfer exogeneous RNA and proteins to recipient cells has been observed (Alvarez-Erviti et al., 2011; Shtam et al., 2013; Haney et al., 2015; Srivastava et al., 2016). The role of exosomes in the formation, development, and repression of different types of cancer is of great interest (Webber et al., 2015; Yu et al., 2015).

The $\mathrm{p} 53$ protein has not been identified previously among exosome proteins that are secreted by cell lines (Kalra et al., 2012; Lasser et al., 2012). The results of numerous studies demonstrate that, by enhancing the expression of some genes in cells, it is possible to increase the amount of the protein that is encoded by them in the exosomes (Graner et al., 2009; Mukhopadhyay and Mak, 2009; Staubach et al., 2009; Meckes et al., 2010; Adamczyk et al., 2011; Gyorgy et al., 2011; Higginbotham et al., 2011). In this study, we observed p53 in exosomes that were obtained from cells with increased expression of the corresponding gene and tried to answer the question of whether the exosomes from cells with wild-type p53 could affect proliferation of p53-negative cells.

Using the p53 protein as an example, we confirmed the possibility of an increase in the protein content in exosomes by changing its expression in the cells. However, the data that were obtained for mutant p53 (p53 4 Y126) may not fully correspond to wild-type p53. We actually observed that GFPp53 3 Y126 was present not only in the nucleus, but also in the cell cytoplasm (Fig. 1b). The literature states that cytoplasmic proteins are included into the secreted vesicles with higher probability (Kalra et al., 2012). The fact that p53 has not been found in exosomes before may be accounted for by low expression of this short-living transcription factor, which is predominantly localized in the nucleus, in its unmutated state. Perhaps there are other explanations. In this study we have observed endogenous p53 in exosomes that were obtained from HT-1080 cells with wild-type p53. Our previous results are evidence of high expression of p53 in these cells as compared to other cells with wild-type p53 (Kovalev et al., 2015; http://p53.free.fr/Database/Cancer_cell_lines/p53_cell_lines.html). The high expression of p53 in producer cells and the use of Western blotting for its detection, which is not a conventional method for proteomic investigation of exosomes, are likely to have made it possible to detect p53 in exosomes. On the whole, the data that we obtained indicate a potential presence of p53 in exosomes of body fluids, in particular, in exosomes that are produced by cells with high expression of this protein. In view of this, we tried to detect p53 in exosomes of human blood plasma. The result is quite intriguing: although p53 accumulation was possible to determine in recipient cells only by confocal microscopy, this protein was surely present in exosomes of human blood plasma.

As has been shown in several previous studies, exosomes are potential protein transporters that are involved in oncogenesis (Soldevilla et al., 2014; Gopal et al., 2016; You et al., 2016). In view of this, we attempted to answer the question of whether the exosomes from cells with wild-type p53 can affect the recipient cells. The survival of the HT-1080 or HEK293 cells with wild-type p53 that were co-cultured with any of the exosomes did not differ from the control. At the same time, the survival of the GL-V or K562 cells without endogenous p53 reduced in the presence of the HEK293 exosomes and, in particular, in the presence of the HT-1080 exosomes. Our results demonstrate for the first time that the exosomes from cell lines with wild-type p53 suppress the growth of p53-negative cells of cancer lines. This indicates the possibility of tumor regression by exosomes that contain endogenous wild-type p53. These results make it possible to suggest that exosomes by transferring one of the most important oncosuppressors between cells can play an important role in the control of oncogenesis.

\section{REFERENCES}


Abels, E.R. and Breakefield, X.O., Introduction to extracellular vesicles: biogenesis, RNA cargo selection, content, release, and uptake, Cell Mol. Neurobiol., 2016, vol. 36, pp. 301-312.

Adamczyk, K.A., Klein-Scory, S., Tehrani, M.M., Warnken, U., Schmiegel, W., Schnolzer, M., and Schwarte-Waldhoff, I., Characterization of soluble and exosomal forms of the EGFR released from pancreatic cancer cells, Life Sci., 2011, vol. 89, pp. 304-312.

Alvarez-Erviti, L., Seow, Y., Yin, H., Betts, C., Lakhal, S., and Wood, M.J., Delivery of SiRNA to the mouse brain by systemic injection of targeted exosomes, Nat. Biotechnol., 2011, vol. 29, pp. 341345 .

Gopal, S.K., Greening, D.W., Hanssen, E.G., Zhu, H.J., Simpson, R.J., and Mathias, R.A., Oncogenic epithelial cell-derived exosomes containing Rac1 and PAK2 induce angiogenesis in recipient endothelial cells, Oncotarget, 2016, vol. 7, pp. 19709-19722.

Graner, M.W., Alzate, O., Dechkovskaia, A.M., Keene, J.D., Sampson, J.H., Mitchell, D.A., and Bigner, D.D., Proteomic and immunologic analyses of brain tumor exosomes, FASEB J., 2009, vol. 23, pp. 1541-1557.

Grange, C., Tapparo, M., Collino, F., Vitillo, L., Damasco, C., Deregibus, M.C., Tetta, C, Bussolati, B., and Camussi, G., Microvesicles released from human renal cancer stem cells stimulate angiogenesis and formation of lung premetastatic niche, Cancer Res., 2011, vol. 71, pp. 5346-5356.

Gyorgy, B., Szabo, T.G., Pasztoi, M., Pal, Z., Misjak, P., Aradi, B., Laszlo, V., Pallinger, E., Pap, E., Kittel, A., Nagy, G., Falus, A., and Buzas, E.I., Membrane vesicles, current state-of-the-art: emerging role of extracellular vesicles, Cell Mol. Life. Sci., 2011, vol. 68, pp. 2667-2688.

Haney, M.J., Klyachko, N.L., Zhao, Y., Gupta, R., Plotnikova, E.G., He, Z., Patel T., Piroyan, A., Sokolsky, M., Kabanov, A.V., and Batrakova, E.V., Exosomes as drug delivery vehicles for Parkinson's disease therapy, J. Control. Release, 2015, vol. 207, pp. 18-30.

Higginbotham, J.N., Demory Beckler, M., Gephart, J.D., Franklin, J.L., Bogatcheva, G., Kremers, G.J., Piston, D.W., Ayers, G.D., McConnell, R.E., Tyska, M.J., and Coffey, R.J., Amphiregulin exosomes increase cancer cell invasion, Curr. Biol., 2011, vol. 21, pp. 779-786.

Hollstein, M., Rice, K., Greenblatt, M.S., Soussi, T., Fuchs, R., Sorlie, T., Hovig, E., SmithSorensen, B., Montesano, R., and Harris, C.C., Database of p53 gene somatic mutations in human tumors and cell lines, Nucleic Acids Res., 1994, vol. 22, pp. 3551-3555.

Huang, S.H., Li, Y., Zhang, J., Rong, J., and Ye, S., Epidermal growth factor receptorcontaining exosomes induce tumor-specific regulatory T cells, Cancer Invest., 2013, vol. 31, pp. 330 335 .

Jorgensen, M.M., Bak, R., and Varming, K., Potentials and capabilities of the extracellular vesicle (EV) array, J. Extracell. Vesicles, 2015, vol. 4, p. 26048. doi:10.3402/jev.v4.26048

Kalra, H., Simpson, R.J., Ji, H., Aikawa, E., Altevogt, P., Askenase, P., Bond, V.C., Borra`s, F.E., Breakefield, X., Budnik, V., Buzas, E., Camussi, G., Clayton, A., Cocucci, E., Falcon-Perez, J.M., Gabrielsson, S., Gho, Y.S., Gupta, D., Harsha, H.C., Hendrix, A., Hill, A.F., Inal, J.M., Jenster, G., Kramer-Albers, E.M., Lim, S.K., Llorente, A., Lotvall, J., Marcilla, A., Mincheva-Nilsson, L., Nazarenko, I., Nieuwland, R., Noltet, Hoen, E.N., Pandey, A., Patel, T., Piper, M.G., Pluchino, S., Prasad, T.S., Rajendran, L., Raposo, G., Record, M., Reid, G.E., Sanchez-Madrid, F., Schiffelers, R.M., Siljander, P., Stensballe, A., Stoorvogel, W., Taylor, D., Thery, C., Valadi, H., van, Balkom, B.W., Vazquez, J., Vidal, M., Wauben, M.H., Yanez- Mo, M., Zoeller, M., and Mathivanan, S., Vesiclepedia: a compendium for extracellular vesicles with continuous community annotation, PLoS Biol., 2012, vol. 10, p. e1001450.

Keerthikumar, S., Chisanga, D., Ariyaratne, D., AI Saffar, H., Anand, S., Zhao, K., Samuel, M., Pathan, M., Jois,M., Chilamkurti, N., Gangoda, L., and Mathivanan, S., ExoCarta: a web-based compendium of exosomal cargo, J. Mol. Biol., 2016, vol. 428, pp. 688-692. 
Kobayashi, M., Salomon, C., Tapia, J., Illanes, S.E., Mitchell, M.D., and Rice, G.E., Ovarian cancer cell invasiveness is associated with discordant exosomal sequestration of Let-7 miRNA and miR-200, J. Transl. Med., 2014, vol. 12, p. 4.

Kovalev, R.A., Shtam, T.A., Karelov, D.V., Burdakov, V.S., Volnitskiy, A.V., Makarov, E.M., and Filatov, M.V., Histone deacetylase inhibitors cause the TP53-dependent induction of p21/Waf1 in tumor cells carrying mutations in TP53, Cell Tiss. Biol., 2015, vol. 9, no. 3, pp. 191-197.

Lasser, C., Eldh, M., and Lotvall, J., Isolation and characterization of RNA-containing exosomes, J. Vis. Exp., 2012,vol. 59, p. e3037.

Lespagnol, A., Duflaut, D., Beekman, C., Blanc, L., Fiucci, G., Marine, J.C., Vidal, M., Amson, R., and Telerman, A., Exosome secretion, including the DNA damageinduced p53-dependent secretory pathway, is severely compromised in TSAP6/Steap3-null mice, Cell Death. Differ., 2008, vol. 15, pp. $1723-1733$.

Liang, Y., Liu, J., and Feng, Z., The regulation of cellular metabolism by tumor suppressor p53, Cell Biosci., 2013, vol. 3, p. 9.

Lim, J.W., Mathias, R.A., Kapp, E.A., Layton, M.J., Faux,M.C., Burgess, A.W., Ji, H., and Simpson, R.J., Restoration of full-length APC protein in SW480 colon cancer cells induces exosomemediated secretion of DKK-4, Electrophoresis, 2012, vol. 33, pp. 1873-1880.

Meckes, D.G., Shair, K.H., Marquitz, A.R., Kung, C.P., Edwards, R.H., and Raab-Traub, N., Human tumor virus utilizes exosomes for intercellular communication, Proc. Natl. Acad. Sci. U. S. A., 2010, vol. 107, pp. 20370-20375.

Mukhopadhyay, U.K. and Mak, A.S., p53: is the guardian of the genome also a suppressor of cell invasion, Cell Cycle, 2009, vol. 8, p. 2481.

Naghibalhossaini, F., Hosseini, H.M., Mokarram, P., and Zamani, M., High frequency of genes promoter methylation, but lack of BRAF V600E mutation among iranian colorectal cancer patients, Pathol. Oncol. Res., 2011, vol. 17, pp. 819-825.

Naryzhny, S.N., Blue Dry Western: simple, economic, informative, and fast way of immunodetection, Anal. Biochem., 2009, vol. 392, pp. 90-95.

Neubauer, A., He, M., Schmidt, C.A., Huhn, D., and Liu, E.T., Genetic alterations in the p53 gene in the blast crisis of chronic myelogenous leukemia: analysis by polymerase chain reaction based techniques, Leukemia, 1993, vol. 7, pp. 593-600.

Raimondo, F., Morosi, L., Chinello, C., Magni, F., and Pitto, M., Advances in membranous vesicle and exosome proteomics improving biological understanding and biomarker discovery, Proteomics, 2011, vol. 11, pp. 709-720.

Raposo, G. and Stoorvogel, W., Extracellular vesicles: exosomes, microvesicles, and friends, J. Cell Biol., 2013, vol. 200, pp. 373-383.

Shtam, T.A., Kovalev, R.A., Varfolomeeva, E.Yu., Makarov, E.M., Kil, Yu.V., and Filatov, M.V., Exosomes are natural carriers of exogenous sirna to human cells in vitro, Cell Commun. Signal., 2013, vol. 11, p. 88.

Soldevilla, B., Rodriguez, M., San, Millan, C., Garcia, V., Fernandez-Perianez, R., GilCalderon, B., Martin, P., Garcia-Grande, A., Silva, J., Bonilla, F., and Dominguez, G., Tumor-derived exosomes are enriched in DeltaNp73, which promotes oncogenic potential in acceptor cells and correlates with patient survival, Hum. Mol. Genet., 2014, vol. 3, pp. 467-478.

Srivastava, A., Babu, A., Filant, J., Moxley, K.M., Ruskin, R., Dhanasekaran, D., Sood, A.K., McMeekin, S., and Ramesh, R., Exploitation of exosomes as nanocarriers for gene-, chemo-, and immune-therapy of cancer, J. Biomed. Nanotechnol., 2016, vol. 12, pp. 1159-1173.

Staubach, S., Razawi, H., and Hanisch, F.G., Proteomics of MUC1-containing lipid rafts from plasma membranes and exosomes of human breast carcinoma cells MCF-7, Proteomics, 2009, vol. 9, pp. 2820-2835. 
Ung, T.H., Madsen, H.J., Hellwinkel, J.E., Lencioni, A.M., and Graner, M.W., Exosome proteomics reveals transcriptional regulator proteins with potential to mediate downstream pathways, Cancer Sci., 2014, vol. 105, pp. 1384-1392.

Vousden, K.H. and Prives, C., Blinded by the light: the growing complexity of p53, Cell, 2009, vol. 137, pp. 413-431.

Webber, J., Yeung, V., and Clayton, A., Extracellular vesicles as modulators of the cancer microenvironment, Semin. Cell Dev. Biol., 2015, vol. 40, pp. 27-34.

You, B., Cao, X., Shao, X., Ni, H., Shi, S., Shan, Y., Gu, Z., and You, Y., Clinical and biological significance of HAX-1 overexpression in nasopharyngeal carcinoma, Oncotarget, 2016, vol. 7, pp. $12505-12524$.

Yu, X., Harris, S.L., and Levine, A.J., The regulation of exosome secretion: a novel function of the p53 protein, Cancer Res., 2006, vol. 66, pp. 4795-4801.

Yu, S., Cao, H., Shen, B., and Feng, J., Tumor-derived exosomes in cancer progression and treatment failure, Oncotarget, 2015, vol. 6, pp. 37151-37168.

\section{FIGURE LEGENDS}

Fig. 1. Results of the detection of p53-GFP in HEK293-GFP-p53 cells and in exosomes that are produced by these cells. (a) Visualization of p53-GFP in HEK293 cells before and after introduction of the GFP-p53 $\Delta$ Y126 plasmid; (b) detection of p53 by immunoblotting.

Fig. 2. Visualization of the presence and transfer of endogenous p53 in exosomes. (a) Detection of endogenous p53 in cells of different lines and the corresponding exosomes by immunoblotting; (b) demonstration of exosome transfer of p53 from HT-1080 cells to GL-V cells that do not have p53 by immunofluorescent staining of p53 and confocal microscopy (red signal). DAPI was used to visualize nuclei (blue signal).

Fig. 3. Immunofluorescent detection of $p 53$ in GL-V cells before and after their coculturing with exosomes of human blood plasma. (a) Gl-V cells before coculturing with exosomes; (b) control cells of the GL-V line after coculturing with exosomes that were treated according to the same technique, but without application of antibodies against p53; and (c) GL-V cells after coculturing with exosomes. To visualize cell nuclei, DAPI (blue signal) was used; red signal is p53.

Fig. 4. Survival rate of Gl-V, K562, HEK293, and HT-1080 cells upon their cultivation in the presence of exosomes of one of these cell lines. (1) Control, (2) cultivation in the presence of exosomes of GL-V cells, (3) cultivation in the presence of exosomes of K562 cells, (4) cultivation in the presence of exosomes of HEK293 cells, and (5) cultivation in the presence of exosomes of HT-1080 cells. 
FIGURES

Fig. 1.

(a)

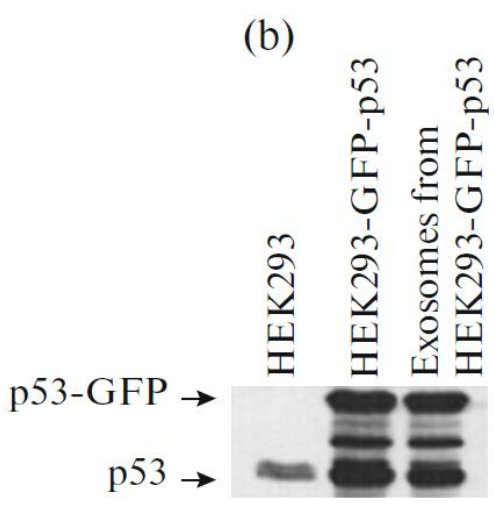

Fig. 2

HEK293-GFP-p53

HEK293

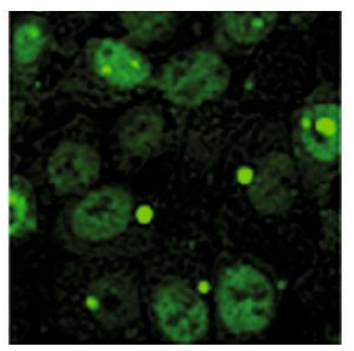

(b)
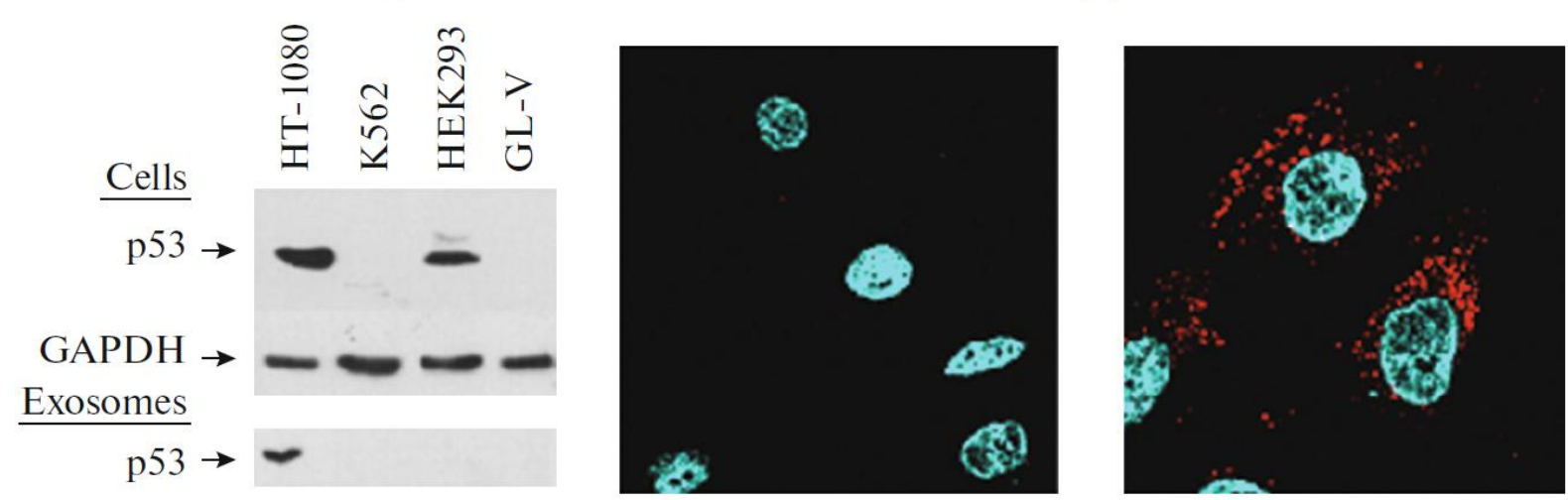

GL-V

GL-V + HT-1080 exosomes

Fig. 3

(a)

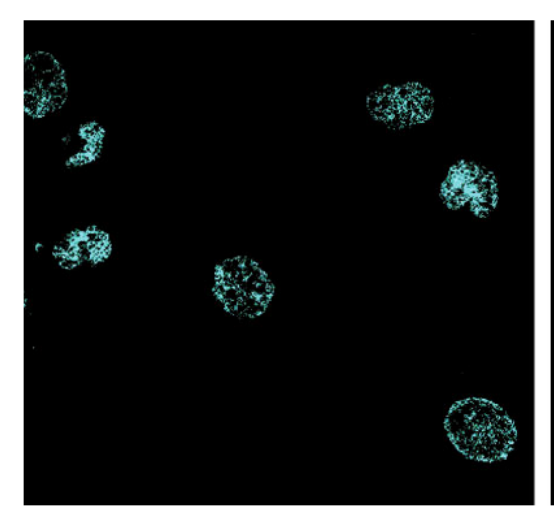

(b)

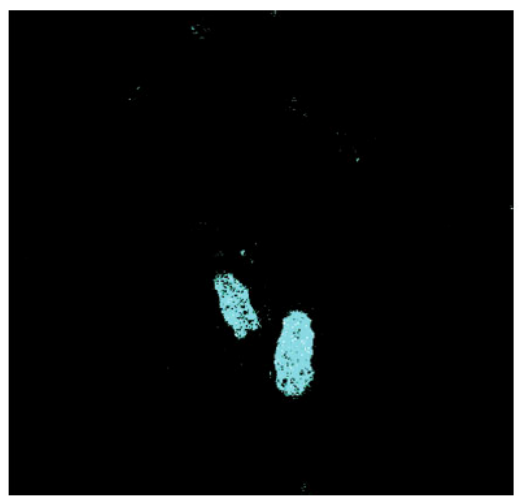

(c)

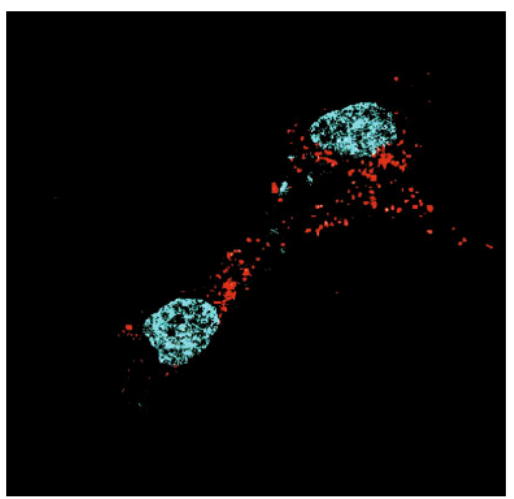


Fig. 4

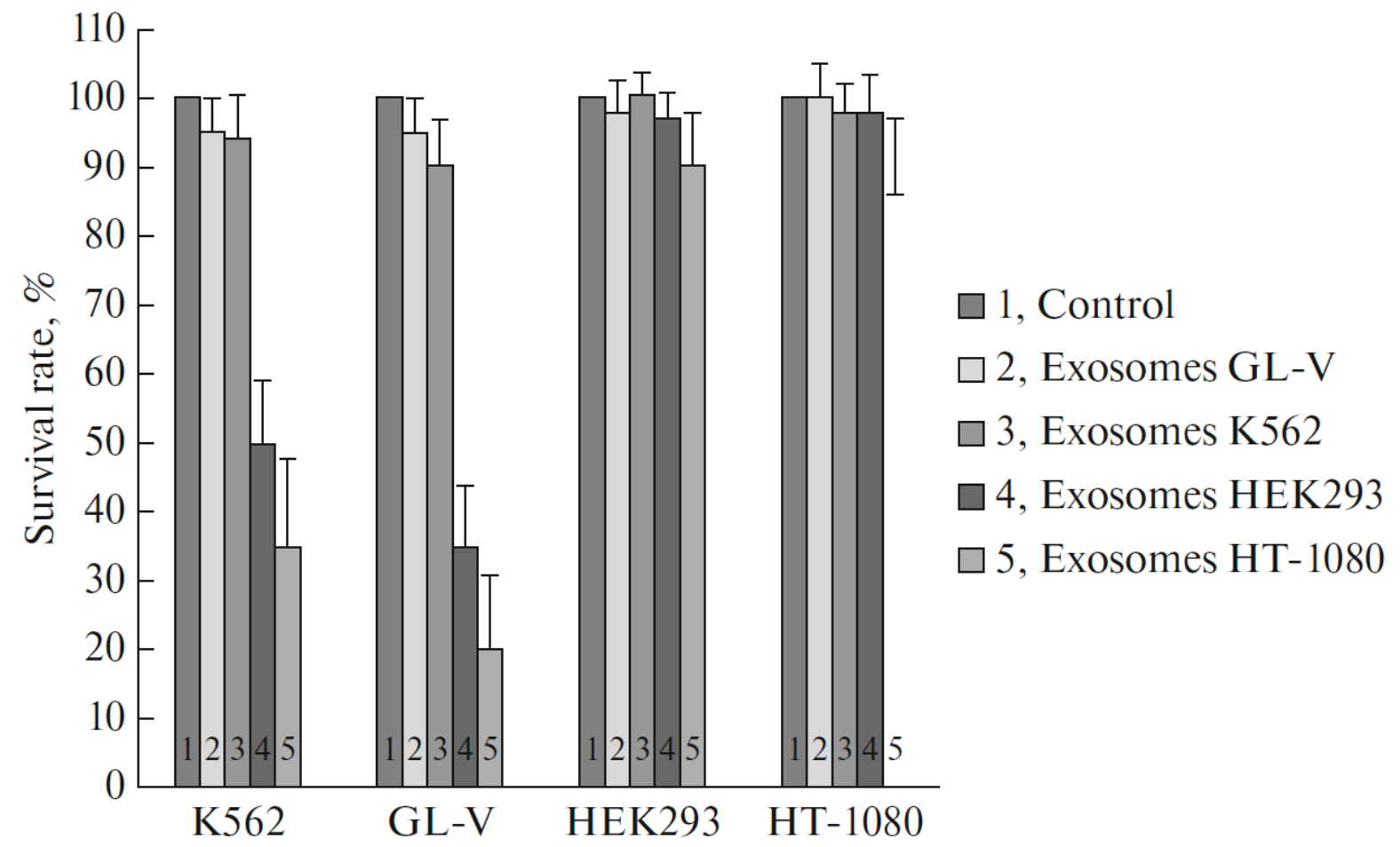

